OPEN ACCESS

Edited by:

Marco Falasca,

Curtin University, Australia

Reviewed by:

Alejandro Piscoya,

Peruvian University of Applied

Sciences, Peru

Michele Barone,

Università degli studi di Bari Aldo

Moro, Italy

*Correspondence:

Dong Shang

shangdong@dmu.edu.cn

Specialty section:

This article was submitted to

Gastrointestinal Sciences,

a section of the journal

Frontiers in Physiology

Received: 27 June 2017 Accepted: 07 September 2017 Published: 21 September 2017

Citation:

Xiang H, Tao X, Xia S, Qu J, Song H, Liu J and Shang D (2017) Targeting MicroRNA Function in Acute

Pancreatitis. Front. Physiol. 8:726. doi: 10.3389/fphys.2017.00726

\section{Targeting MicroRNA Function in Acute Pancreatitis}

\author{
Hong Xiang ${ }^{1,2}$, Xufeng Tao $^{3}$, Shilin Xia ${ }^{4}$, Jialin $Q u^{4}$, Huiyi Song ${ }^{4}$, Jianjun Liu ${ }^{4}$ and \\ Dong Shang ${ }^{1,2 *}$
}

\begin{abstract}
${ }^{1}$ College of Integrative Medicine, Dalian Medical University, Dalian, China, ${ }^{2}$ Department of General Surgery, First Affiliated Hospital of Dalian Medical University, Dalian, China, ${ }^{3}$ College of Pharmacy, Dalian Medical University, Dalian, China, ${ }^{4}$ Clinical Laboratory of Integrative Medicine, First Affiliated Hospital of Dalian Medical University, Dalian, China
\end{abstract}

Acute pancreatitis (AP) is a common gastrointestinal disorder that featured by acute inflammatory responses leading to systemic inflammatory response syndrome (SIRS) or multiple organ failure. A worldwide increase in annual incidence has been observed during the past decade with high acute hospitalization and mortality. Lack of any specific treatment for AP, even to this day, is a reminder that there is much to be learned about the exact pathogenesis of AP. Fortunately, the discovery of microRNA (miRNA) has started an entirely new thought process regarding the molecular mechanism associated with the disease processes. Given the extensive effort made on miRNA research, certain types of miRNA have been identified across a variety of biological processes, including cell differentiation, apoptosis, metabolism, and inflammatory responses. Mutations in miRNA sequences or deregulation of miRNA expression may contribute to the alteration of a pivotal physiological function leading to AP. Designing miRNA-related tools for AP diagnosis and treatment presents a novel and potential research frontier. In this mini-review, we summarize the current knowledge of various miRNAs closely interacting with AP and the possible development of targeted miRNA therapies in this disease, which may benefit the development of potential disease biomarkers and novel treatment targets for future medical implications.

Keywords: microRNA, acute pancreatitis, biomarker, target gene, therapeutic tool

\section{INTRODUCTION}

Acute pancreatitis (AP) is a type of sterile inflammation of the pancreas initiated by dysfunction of the exocrine pancreas that breaks the balance between protective enzymes and stress signals (Lankisch et al., 2015). In the majority of patients, the condition is mild and self-limiting, but $\sim 20-$ $30 \%$ of cases eventually develop a severe course with high mortality despite treatment (Bakker et al., 2014). As a rapidly evolving condition, the severity of AP can change quickly within an extremely short amount of time (Mentula and Leppaniemi, 2014). The current management of AP usually consists of combined treatments of nutritional support, analgesics, and protease inhibitors; unfortunately, these therapies exhibit limited efficacy due to their lack of targeting (Tenner et al., 2013; Yokoe et al., 2015). Therefore, it's urgent to search novel diagnostic and therapeutic methods for AP.

The discovery of microRNA (miRNA) has started an entirely new thought process regarding AP diagnosis and treatment. miRNA is a single-stranded non-coding RNA that controls the expression of the majority of genes through either cleavage or translational repression (Iorio and Croce, 2009). 
There is emerging evidence that altered miRNA expression may lead to the alteration of pivotal physiological functions that participate in inflammation infiltration and complication of multiple diseases, including AP ( $\mathrm{Hu}$ et al., 2015; KusnierzCabala et al., 2015; Maltby et al., 2016). Therefore, we summarize the interlinked relationships between miRNA and AP to offer a possible diagnostic and therapeutic tool for managing this disease in this mini-review.

\section{MIRNA EXPRESSION IN THE PANCREAS}

Many miRNAs are often evolutionarily conserved, and limited in their expression to certain stages in development or to certain cell or tissue types (Sood et al., 2006). Therefore, the ability to determine miRNA expression in the exocrine pancreas will prove valuable in helping to understand the putative roles played by miRNA in AP. Szafranska et al. reported that the expression of miR-216 and miR-217 was identified as a characteristic of human pancreas tissue (Szafranska et al., 2007), which are almost exclusively expressed in rat pancreas (Wang et al., 2017). As normal pancreas consists of $\sim 90 \%$ acinar cells, it is easy to think that miR-216 (including highly homologous miR-216a and miR216b) and miR-217 are enriched in the acinar cells and play a key role in exocrine pancreatic function (Meher et al., 2015; Rouse et al., 2017). Moreover, Kong et al. quantified the relative concentration of miR-216a in pancreas tissues sampled from healthy rats, and found it was 128 -fold higher than that in kidney, which had the next highest concentration, indicating that miR216a may contribute to distinguishing pancreatic diseases from other tissue diseases (Kong et al., 2010). Dixit et al. identified that miR-148a-3p, miR-375-3p, miR-217-5p, and miR-200a-3p are the most abundant miRNAs at basal state, whereas miR421-3p, miR-24-5p, and miR-29a-5p are the least abundantly expressed in mouse pancreatic acinar cells (Dixit et al., 2016). In addition, Let-7b and miR-495 and their target genes control a transcriptional network that drives pancreatic acinar cell differentiation, which are critical to ensuring acinar homeostasis (Prevot et al., 2013). Due to these correlations of miRNAs in the regulation of physiological processes in pancreas, understanding the modulation of miRNAs expression in AP is crucial.

\section{ABERRANT MIRNA EXPRESSION LEVELS IN ACUTE PANCREATITIS}

Early diagnosis of the severity of AP can identify a potential severe acute pancreatitis (SAP) risk as early as possible and provide a high clinical value for improving patient prognosis (Lee et al., 2013). At present, the pancreatic biomarkers amylase and lipase are commonly used in the early prediction of AP, but they are often limited in clinical practice due to their own limitations (Treacy et al., 2001; Huang et al., 2016). Accumulating evidence has shown that abnormal expression of miRNA related to AP pathogenesis can serve as a candidate biomarker of this disease diagnosis and prognosis (Kong et al., 2010; An et al., 2014; Dixit et al., 2016; Zhang et al., 2017). The aberrant miRNA expression patterns in animal models and patients with AP are listed in Table 1.

\section{Animals}

Based on a comprehensive analysis of miRNA expression profiles, miR-21-3p was significantly overexpressed in mouse pancreatic acinar cells exposed to different pancreatic toxicants (Dixit et al., 2016). Except for tissue specificity, miRNAs can be expressed stably in circulation (Lawrie et al., 2008; Arroyo et al., 2011). It has been reported that the plasma levels of exocrine pancreas-enriched miR-216a, miR-216b, and miR217 significantly increased after induction of AP or exocrine pancreatic injury (EPIJ) in rodents and dog (Endo et al., 2013; Goodwin et al., 2014; Usborne et al., 2014; Calvano et al., 2016; Rouse et al., 2017; Wang et al., 2017). Smith et al. considered that miR-216a-5p, miR-375-3p, miR-148a-3p, miR216b-5p, and miR-141-3p continued to elevate in the serum of rats or dogs longer than amylase or lipase and had a large dynamic range (Smith et al., 2016). After cerulein injection, an inverse relationship between plasma levels of miR-122 and erythropoietin (EPO) was observed in mice (Rivkin et al., 2016). Moreover, using an AP rat model, Blenkiron et al. discovered that the expression of miRNAs: miR-375, miR-217, miR-148a, miR-216a, miR-122, miR-214, and miR-138 were increased in mesenteric lymph fluid with a positive correlation with AP severity (Blenkiron et al., 2014). Thus, ever more experimental data regarding AP are currently being generated. However, these discovered numerous miRNA in animals AP are needed further validation and research in clinical settings.

\section{Patients}

In human, serum miR-92b, miR-10a, and miR-7 were reported to reduce during $\mathrm{AP}$, and gave an area under the curve (AUC) value of 0.69 (Liu et al., 2014). Research from Kusnierz-Cabala et al. showed highly abundant miR-126-5p, miR-148a-3p, miR-216a$5 \mathrm{p}$, miR-551b-5p, and miR-375 in the serum of SAP patients, as well as miR-216a-5p, miR-551b-5p, and miR-375 in mild acute pancreatitis (MAP) patients. Further, receiver operating characteristic (ROC) curve analysis revealed that miR-126-p and miR-551b-5p may be used as potential markers for predicting AP severity with a good AUC (sensitivity $=60.0 \%$, specificity $=$ $87.1 \%$; and sensitivity $=69.2 \%$, specificity $=72.6 \%$; KusnierzCabala et al., 2015). During hypertriglyceridemia- induced AP (HTAP), An et al. observed significant up-regulation in the serum concentration of the following miRNAs: miR24-3p, miR-361-5p, miR-1246, and miR-222-3p; miR-181a-5p were constantly downregulated. The AUC for all five overlapping miRNA were 0.889 $($ sensitivity $=100 \%$; specificity $=83.3 \%), 0.722$ (sensitivity $=$ $85 \%$; specificity $=90 \%), 0.917$ (sensitivity $=98 \%$; specificity $=$ $92 \%), 0.833$ (sensitivity $=100 \%$; specificity $=83.3 \%$ ), and 0.972 (sensitivity $=100 \%$; specificity $=83.3 \%$ ), successively. These results demonstrated that the expressions of these miRNAs, especially miR-181a-5p, can be used to accurately evaluate the progression of HTAP. Moreover, miR-181a-5p has a positive correlation with $\mathrm{Ca}^{2+}$ but a negative correlation with triglyceride (TG), total cholesterol (TC), and fasting blood glucose (FBG) (An et al., 2014). In summary, as shown in Table 1, these 
TABLE 1 | Aberrant miRNA expression levels in acute pancreatitis.

\begin{tabular}{|c|c|c|}
\hline miRNA expressions & Samples & References \\
\hline $\operatorname{miR}-216 a \uparrow$ & Rat/patients plasma & Kong et al., 2010; Blenkiron et al., 2014; Zhang et al., 2017 \\
\hline $\operatorname{miR}-21-3 p \uparrow$ & Mouse pancreatic acini & Dixit et al., 2016 \\
\hline $\operatorname{miR}-122 \uparrow$ & Mice plasma & Rivkin et al., 2016 \\
\hline $\mathrm{miR}-216 \mathrm{a} / \mathrm{miR}-216 \mathrm{~b} \uparrow$ & Rat Plasma & Endo et al., 2013 \\
\hline miR-216a/miR-375 个 & Rat serum & Usborne et al., 2014 \\
\hline miR-216a/miR-217 $\uparrow$ & Rat/mice serum & Goodwin et al., 2014; Wang et al., 2017 \\
\hline miR-216a-5p/miR-375-3p/miR-148a-3p/miR-216b-5p/miR-141-3p $\uparrow$ & Rat/dog serum & Smith et al., 2016 \\
\hline $\mathrm{miR}-216 \mathrm{a} / \mathrm{miR}-216 \mathrm{~b} / \mathrm{miR}-217 \uparrow$ & Rat/canine serum & Calvano et al., 2016; Rouse et al., 2017 \\
\hline miR-375/miR-217/miR-148a/miR-216a/miR-122/miR-214/miR-138 个 & Rat Mesenteric Lymph & Blenkiron et al., 2014 \\
\hline miR-126-5p/miR-148a-3p/miR-216a-5p/miR-551b-5p/miR-375 个 & SAP patients serum & Kusnierz-Cabala et al., 2015 \\
\hline miR-216a-5p/miR-551b-5p/miR-375个 & MAP patients serum & Kusnierz-Cabala et al., 2015 \\
\hline miR-92b/miR-10a/miR-7 $\downarrow$ & Patients serum & Liu et al., 2014 \\
\hline miR-24-3p/miR-361-5p/miR-1246/ miR-222-3p $\uparrow$ miR-181a-5p $\downarrow$ & HTAP Patients serum & An et al., 2014 \\
\hline
\end{tabular}

clinical studies indicate that the potential miRNA biomarkers of AP include miR-92b, miR-126-5p, miR24-3p, miR-181a-5p, and so on.

Due to the specificity and sensitivity of miRNA in the regulation of the AP process, it's better than conventional biomarkers with poor tissue and cell specificity (Beuvink et al., 2007; Tombol et al., 2009). Although, it is generally accepted that RNA is easily degraded when it is isolated from RNase-rich tissue samples, such as the pancreas, Kim et al. believed that RNA degradation due to extended storage at room temperature has no effect on the predictive power of the tissue-specific miRNA quantitative reverse transcription polymerase chain reaction (QRTPCR) predictor (Kim et al., 2011). Furthermore, several miRNAs are able to withstand a variety of harsh environments, such as repeated freezing and thawing or high acidic or basic environments with extreme $\mathrm{pH}$ (Machado et al., 2015). Compared with other biomarkers, miRNA expression is stable in body fluids, especially in the bloodstream, generating interest in the utilization of miRNA as serum- and/or plasma-based biomarkers of AP diagnosis and patient stratification (Mitchell et al., 2008; Kong et al., 2010; Liu et al., 2014). However, various miRNAs are abnormally presented in the disease condition of AP; thus, a detailed miRNA profile should be created that also refers to other diagnostic methods to avoid misinterpretation.

\section{miRNA REGULATING ACUTE PANCREATITRIS-RELATED GENE EXPRESSION}

Recently, some miRNAs were found to regulate the expression of target genes in complicated AP, and the detailed mechanism is shown in Figure 1.

\section{Apoptosis/Necrosis}

Apoptosis and necrosis are the two main patterns of pancreatic acinar cell death during AP, and they may interchange with one another under appropriate conditions (Bhatia, 2004; Mareninova et al., 2006). Apoptosis maintains membrane integrity without stimulating the immune system, whereas necrotic cells release damage- associated molecular pattern molecules (DAMPs) that trigger an inflammatory cascade (Bhatia, 2004).

Data from in vivo and in vitro models of acute edematous pancreatitis (AEP) have shown that the expression levels of miR-22 and miR-135a increased significantly compared with the normal group, which play a protective role in AEP through the pro-apoptosis activity in pancreatic acinar cells by inhibiting the expression of their target gene, ErbB3 and Ptk2, respectively (Qin et al., 2014). Tyrosine-phosphorylated ErbB3 shows higher affinity for phosphatidylinositol-4, 5-bisphosphate 3-kinase (PI3K), so activated ErbB3 leads to a strong activation of the $\mathrm{PI} 3 \mathrm{~K} /$ serine/threonine kinase (Akt) signaling pathway that can result in apoptosis resistance (Soltoff et al., 1994; Roy et al., 2010). The activation of PI3K/Akt is also necessary for activation of intrapancreatic trypsinogen (Fischer et al., 2007). Ptk2 gene encodes focal adhesion kinase (FAK) protein, and the activation of this gene may be an early important step in cell death (Alisi et al., 2012). Many studies have demonstrated that genetic ablation of Ptk2 and reducing the FAK protein level could promote drug-inducing apoptosis via markedly enhancing caspase 9 and caspase 3 activities (Yuan et al., 2010; Xie et al., 2011; Shi et al., 2012). Evidence from the study of $\mathrm{Fu}$ et al. had demonstrated that apoptotic rate and TNFRSF1A expression were obviously elevated following the up-regulation of miR-29a expression in AR42J cells treated with recombinant rat TNF- $\alpha$ (Fu et al., 2016). TNFRSF1A, as the target gene of miR-29a, encodes the tumor necrosis factor receptor 1 (TNFR1) protein that is the major signaling receptor for TNF- $\alpha$ (Borghini et al., 2011). The combination of TNF- $\alpha$ to TNFR1 immediately activates nuclear factor-kappa B (NF-кB) and subsequent apoptosis (Wajant et al., 2003).

The necrosis rate of pancreatic acinar cells and the following inflammation correlate with the mortality of patients with acute necrotizing pancreatitis (ANP) (Xu et al., 2015). Increasing research has demonstrated the function of miRNAs in pancreatic acinar cell necrosis, indicating that miRNA may be a potential 


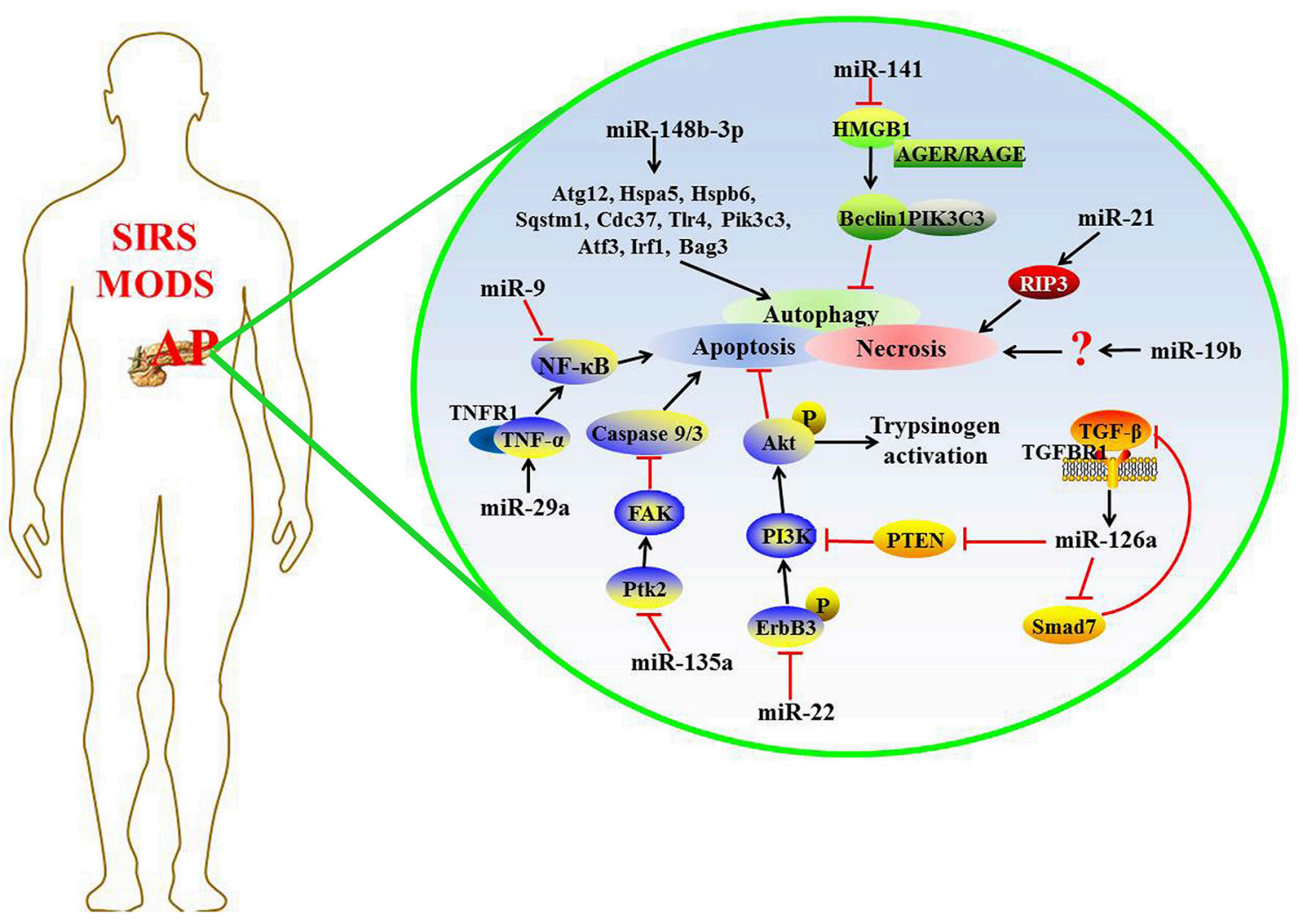

FIGURE 1 | The possible mechanisms of miRNAs regulating target expression in complicated AP.

target for drug development against AP (Ma et al., 2015; Hu et al., 2016). The increased expression of miR-19b in ANP rats or taurolithocholic acid 3-sulfate disodium salt (TLC-S)treated AR42J cells, could promote cellular necrosis; otherwise, deleting miR-19b could decrease the necrosis rate ( $\mathrm{Hu}$ et al., 2016). Ma et al. report that miR-21 is overexpressed in a mouse model of AP; miR-21 inhibition protects against caerulein- or L-arginine-induced AP and effectively reduced disease severity. Further, silencing the expression of miR-21 is protective in TNFinduced SIRS. MiR-21 promotes TNF- $\alpha$-induced necroptosis, a pathologic condition involving receptor-interacting protein 3 (RIP3)-dependent regulated necrosis (Ma et al., 2015). RIP3 is a component of the necrosome, which can be directly cleaved and inactivated by caspase 8 to negatively regulate necroptosis induced by TNF- $\alpha$ (Kaiser et al., 2011). Thus, miRNAs critically involved in the apoptosis and/or necrosis processes of AP.

\section{Autophagy}

Autophagy is a form of programmed cell death in the evolutionary process, and the main function of it is lysosomal self-digestion of a cell's own components in response to external stimuli (Jones et al., 2013; Vernon and Tang, 2013). Many studies have shown that autophagy is involved in the progression of AP, but its function in the course of AP is still controversial. Previous studies reported that selective autophagy plays a cytoprotective role by eliminating excess zymogen activation, and reduces pancreatic cell death induced by trypsin at the onset of AP (Grasso et al., 2011). Another opposite view is that autophagy contributes to the formation of acinar cell vacuoles and to the activation of trypsinogen as the primary mechanism underlying the pathogenesis of AP (Gukovsky et al., 2012).

miRNA preserves the autophagy process via regulating the expression of autophagy-associated genes. Using an in vitro acinar cell autophagy model, Gao et al. identified that downregulated miR-148b-3p may be a moderator in the autophagic process, and 10 autophagy-related genes among miR148b-3p targets were identified through data mining technology: Sqstm1, Cdc37, Tlr4, Atg12, Hspa5, Hspb6, Pik3c3, Atf3, Irf1, and Bag3. These target genes indirectly affected the regulation of autophagy by interfering with key genes related to the autophagic signaling pathway (Gao et al., 2016). However, further exploration is required to confirm the regulatory effects and mechanism of miR-148b-3p and its target genes on the autophagic process. Recent research reported that in L-arginineinduced AP mice, the pancreatic tissue injury in mice using miR141 adenoviral vector treatment is much less than normal saline treatment, as are autophagosomal and autolysosomal processes in pancreatic tissues. Mechanistically, miR-141 antagonizes high mobility group box-1 protein (HMGB1) expression and further reduces the downstream protein Beclin-1 level, leading to a block in the process of autophagosomes formation, suggesting that miR-141 may inhibit autophagy through the HMGB1/Beclin-1 
pathway (Zhu et al., 2016). HMGB1 is a conserved nuclear protein that plays subcellular localization-dependent roles in the regulation of autophagy (Tang et al., 2012). Cytosolic HMGB1 is a novel Beclin-1-binding protein to induce autophagy (Tang et al., 2010). Extracellular HMGB1 combines with advanced glycosylation end product-specific receptor (AGER/RAGE) to accelerate the formation of Beclin-1- phosphatidylinositol 3kinase catalytic subunit type 3 (PIK3C3) core autophagic complexes (Kang et al., 2010; Yu et al., 2016). These findings show that miRNA appears to be a promising candidate for study on the mechanisms of autophagy-promoted AP and the gene therapy of AP (Zhu et al., 2016).

\section{TGF- $\beta$ Feedback Pathway}

Transforming growth factor- $\beta$ (TGF- $\beta$ ) is a multifunctional cytokine that participates in a variety of biological processes, including cell apoptosis and immune system regulation (Mikami et al., 2006). It has been reported that TGF- $\beta$ and its receptors are up-regulated in patients with AP (Friess et al., 1998; Wildi et al., 2007). The expression of miR-216a increases in a dose-dependent manner in AR42J cells after TGF- $\beta$ stimulation. Meanwhile, the TGF- $\beta$ inhibitor SB431542 can decrease the miR-216a expression in pancreatic tissue and serum in the cerulean-induced AP mouse model. TGF- $\beta$ aggravates AP via up-regulating miR-216a, which targets PTEN and Smad7 (Zhang et al., 2015). PTEN is a suppressor of the PI3K/Akt signaling pathway associated with cell apoptosis (Blanco-Aparicio et al., 2007). Smad7 blocks the TGF- $\beta$ signaling pathway through a negative feedback loop, and it also acts as a cross talk mediator between TGF- $\beta$ signaling and others (Yan and Chen, 2011). Therefore, TGF- $\beta / \mathrm{miR}-216 \mathrm{a}$ signaling pathway regulates multiple biological processes in AP.

\section{NF-кB Signaling Pathway}

Mesenchymal stem cells (MSCs) belong to the stem cell family and have been widely used as gene delivery vehicle of delivering exogenous genes to damaged tissues for a cellbase therapeutic strategy ( $\mathrm{Si}$ et al., 2011). MiR-9 is a key paracrine molecular of bone marrow-derived mesenchymal stem cells (BMSCs), and the up-regulation of it could inhibit the inflammatory response induced by lipopolysaccharide (LPS) in human polymorphonuclear neutrophils (PMN) and peripheral blood mononuclear cells (PBMC) (Bazzoni et al., 2009). Qian et al. found that miR-9-modified BMSCs (pri-miR-9-BMSCs) significantly reduced pancreatic injury and the activities of serum amylase and lipase in AP rats. Meanwhile, decreased release of inflammatory factors and enhanced regeneration of the necrotized pancreatic tissues are also observed. These results show that miR-9 may be an anti-inflammatory factor involved in the progression of AP. BMSCs deliver miR-9 to the damaged pancreas or PBMCs, which may attenuate SAP targeting of the NF- $\mathrm{B} 1 /$ p50 gene (Qian et al., 2017).

When AP occurs, the damaged pancreatic cells release pro-inflammatory mediators to stimulate macrophages in the pancreas, peritoneum, and other tissues (Gutierrez et al., 2008). Activated macrophages secrete various inflammatory cytokines, resulting in the spread of inflammation (Jaffray et al., 2000; Ni et al., 2014). Therefore, cell-level therapies targeting macrophages may achieve a valuable breakthrough in the treatment of
AP. It has been discovered that intercellular communication plays an essential role in the activation of pancreatitisassociated macrophages (Lundberg et al., 2000). miRNA is thought to be a mediator of intercellular communication that is transported to recipient cells to regulate their functions (Chevillet et al., 2014). Recently, the results from Zhao et al.'s research demonstrated that activated AR42J cells enhanced NF$\kappa \mathrm{B}$ activation in the macrophages by secreting exosomes carrying differentially expressed miRNAs (Zhao et al., 2016). These researches indicate that miRNA appears to regulate the NF- $\kappa$ B promoted-inflammatory responses in AP.

\section{MIRNA AS A POTENTIAL THERAPEUTIC TOOL}

miRNA play key roles in gene expression regulation; thus, manipulating miRNA function in vitro and in vivo is a potential therapy at the genetic level to modulate disease pathogenesis. The discovery of miRNA inhibitors (e.g., anti-miRNAs and miRNA sponges) or enhancers (mimics) interfere with miRNA, increasing or inhibiting translation of miRNA-targeted mRNAs, thus modifying protein expression levels and greatly pushing forward the development of novel drugs (Ebert et al., 2007; Lennox and Behlke, 2011; Robb et al., 2017). Currently, a major restriction to exploiting miRNAs as therapies is the likelihood of undesired side effects due to their biological properties, in which individual miRNAs modulate multiple downstream targets, and interfering with single miRNAs can have broad impacts on multiple cellular pathways simultaneously and will potentially offset the desired therapeutic effects, particularly when systemic drug delivery is used (Baker, 2010). Therefore, a personalized miRNA therapy to maintain other functions without disturbance and optimize drug delivery systems are required in future research.

\section{CONCLUSION}

In this mini-review, we have discussed the promising role of miRNAs in developing more effective therapies for AP apart from acting as potential diagnostic tools. Although, some miRNAs have been discovered to demonstrate a direct or indirect link to AP progression, investigations on applying miRNA in AP treatment remain at the development stage. These basic researches can provide a large number of valuable information for the clinical promotion of miRNA-diagnostic application and the future development of AP-treatment.

\section{AUTHOR CONTRIBUTIONS}

HX, XT, SX, JQ, HS, JL, and DS wrote the manuscript.

\section{FUNDING}

This work was financially supported by the National Natural Science Foundation of China (No. 81373875) and the Key Project Supported by Clinical Ability Construction of Liaoning Province (No. LNCCC-A03-2015). 


\section{REFERENCES}

Alisi, A., Arciello, M., Petrini, S., Conti, B., Missale, G., and Balsano, C. (2012). Focal adhesion kinase (FAK) mediates the induction of pro-oncogenic and fibrogenic phenotypes in hepatitis C virus (HCV)-infected cells. PLoS ONE 7:e44147. doi: 10.1371/journal.pone.0044147

An, F., Zhan, Q., Xia, M., Jiang, L., Lu, G., Huang, M., et al. (2014). From moderately severe to severe hypertriglyceridemia induced acute pancreatitis: circulating miRNAs play role as potential biomarkers. PLoS ONE 9:e111058. doi: 10.1371/journal.pone.0111058

Arroyo, J. D., Chevillet, J. R., Kroh, E. M., Ruf, I. K., Pritchard, C. C., Gibson, D. F., et al. (2011). Argonaute 2 complexes carry a population of circulating microRNAs independent of vesicles in human plasma. Proc. Natl. Acad. Sci. U.S.A. 108, 5003-5008. doi: 10.1073/pnas.1019055108

Baker, M. (2010). RNA interference: homing in on delivery. Nature 464, 1225-1228. doi: 10.1038/4641225a

Bakker, O. J., van Brunschot, S., van Santvoort, H. C., Besselink, M. G., Bollen, T. L., Boermeester, M. A., et al. (2014). Early versus on-demand nasoenteric tube feeding in acute pancreatitis. N. Engl. J. Med. 371, 1983-1993. doi: 10.1056/NEJMoa1404393

Bazzoni, F., Rossato, M., Fabbri, M., Gaudiosi, D., Mirolo, M., Mori, L., et al. (2009). Induction and regulatory function of miR-9 in human monocytes and neutrophils exposed to proinflammatory signals. Proc. Natl. Acad. Sci. U.S.A. 106, 5282-5287. doi: 10.1073/pnas.0810909106

Beuvink, I., Kolb, F. A., Budach, W., Garnier, A., Lange, J., Natt, F., et al. (2007). A novel microarray approach reveals new tissue-specific signatures of known and predicted mammalian microRNAs. Nucleic Acids Res. 35:e52. doi: $10.1093 /$ nar/gkl1118

Bhatia, M. (2004). Apoptosis versus necrosis in acute pancreatitis. Am. J. Physiol. Gastrointest. Liver Physiol. 286, G189-G196. doi: 10.1152/ajpgi.00304.2003

Blanco-Aparicio, C., Renner, O., Leal, J. F., and Carnero, A. (2007). PTEN, more than the AKT pathway. Carcinogenesis 28, 1379-1386. doi: 10.1093/carcin/bgm052

Blenkiron, C., Askelund, K. J., Shanbhag, S. T., Chakraborty, M., Petrov, M. S., Delahunt, B., et al. (2014). MicroRNAs in mesenteric lymph and plasma during acute pancreatitis. Ann. Surg. 260, 341-347. doi: 10.1097/SLA.0000000000000447

Borghini, S., Fiore, M., Di Duca, M., Caroli, F., Finetti, M., Santamaria, G., et al. (2011). Candidate genes in patients with autoinflammatory syndrome resembling tumor necrosis factor receptor-associated periodic syndrome without mutations in the TNFRSF1A gene. J. Rheumatol. 38, 1378-1384. doi: 10.3899/jrheum.101260

Calvano, J., Edwards, G., Hixson, C., Burr, H., Mangipudy, R., and Tirmenstein, M. (2016). Serum microRNAs-217 and -375 as biomarkers of acute pancreatic injury in rats. Toxicology 368-369, 1-9. doi: 10.1016/j.tox.2016.08.009

Chevillet, J. R., Kang, Q., Ruf, I. K., Briggs, H. A., Vojtech, L. N., Hughes, S. M., et al. (2014). Quantitative and stoichiometric analysis of the microRNA content of exosomes. Proc. Natl. Acad. Sci. U.S.A. 111, 14888-14893. doi: 10.1073/pnas.1408301111

Dixit, A. K., Sarver, A. E., Yuan, Z., George, J., Barlass, U., Cheema, H., et al. (2016). Comprehensive analysis of microRNA signature of mouse pancreatic acini: overexpression of miR-21-3p in acute pancreatitis. Am. J. Physiol. Gastrointest. Liver Physiol. 311, G974-G980. doi: 10.1152/ajpgi.00191.2016

Ebert, M. S., Neilson, J. R., and Sharp, P. A. (2007). MicroRNA sponges: competitive inhibitors of small RNAs in mammalian cells. Nat. Methods 4, 721-726. doi: 10.1038/nmeth1079

Endo, K., Weng, H., Kito, N., Fukushima, Y., and Iwai, N. (2013). MiR-216a and miR-216b as markers for acute phased pancreatic injury. Biomed. Res. 34, 179-188. doi: 10.2220/biomedres.34.179

Fischer, L., Gukovskaya, A. S., Penninger, J. M., Mareninova, O. A., Friess, H., Gukovsky, I., et al. (2007). Phosphatidylinositol 3-kinase facilitates bile acid-induced $\mathrm{Ca}(2+)$ responses in pancreatic acinar cells. Am. J. Physiol. Gastrointest. Liver Physiol. 292, G875-G886. doi: 10.1152/ajpgi.00 558.2005

Friess, H., Lu, Z., Riesle, E., Uhl, W., Brundler, A. M., Horvath, L., et al. (1998). Enhanced expression of TGF-betas and their receptors in human acute pancreatitis. Ann. Surg. 227, 95-104. doi: 10.1097/00000658-199801000-00014
Fu, Q., Qin, T., Chen, L., Liu, C. J., Zhang, X., Wang, Y. Z., et al. (2016). miR-29a up-regulation in AR42J cells contributes to apoptosis via targeting TNFRSF1A gene. World J. Gastroenterol. 22, 4881-4890. doi: 10.3748/wjg.v22.i20.4881

Gao, B., Wang, D., Sun, W., Meng, X., Zhang, W., and Xue, D. (2016). Differentially expressed microRNA identification and target gene function analysis in starvation-induced autophagy of AR42J pancreatic acinar cells. Mol. Med. Rep. 14, 590-598. doi: 10.3892/mmr.2016.5240

Goodwin, D., Rosenzweig, B., Zhang, J., Xu, L., Stewart, S., Thompson, K., et al. (2014). Evaluation of miR-216a and miR-217 as potential biomarkers of acute pancreatic injury in rats and mice. Biomarkers 19, 517-529. doi: 10.3109/1354750X.2014.944217

Grasso, D., Ropolo, A., Lo Re, A., Boggio, V., Molejon, M. I., Iovanna, J. L., et al. (2011). Zymophagy, a novel selective autophagy pathway mediated by VMP1USP9x-p62, prevents pancreatic cell death. J. Biol. Chem. 286, 8308-8324. doi: 10.1074/jbc.M110.197301

Gukovsky, I., Pandol, S. J., Mareninova, O. A., Shalbueva, N., Jia, W., and Gukovskaya, A. S. (2012). Impaired autophagy and organellar dysfunction in pancreatitis. J. Gastroenterol. Hepatol. 27(Suppl. 2), 27-32. doi: 10.1111/j.1440-1746.2011.07004.x

Gutierrez, P. T., Folch-Puy, E., Bulbena, O., and Closa, D. (2008). Oxidised lipids present in ascitic fluid interfere with the regulation of the macrophages during acute pancreatitis, promoting an exacerbation of the inflammatory response. Gut 57, 642-648. doi: 10.1136/gut.2007.127472

Hu, L. H., Ji, J. T., and Li, Z. S. (2015). Potential application of miRNAs as diagnostic and therapeutic tools in chronic pancreatitis. J. Cell. Mol. Med. 19, 2049-2057. doi: 10.1111/jcmm.12603

Hu, M. X., Zhang, H. W., Fu, Q., Qin, T., Liu, C. J., Wang, Y. Z., et al. (2016). Functional role of MicroRNA-19b in acinar cell necrosis in acute necrotizing pancreatitis. J. Huazhong Univ. Sci. Technol. Med. Sci. 36, 221-225. doi: 10.1007/s11596-016-1570-2

Huang, J., Qu, H. P., Zheng, Y. F., Song, X. W., Li, L., Xu, Z. W., et al. (2016). The revised Atlanta criteria 2012 altered the classification, severity assessment and management of acute pancreatitis. Hepatobiliary Pancreat. Dis. Int. 15, 310-315. doi: 10.1016/S1499-3872(15)60040-6

Iorio, M. V., and Croce, C. M. (2009). MicroRNAs in cancer: small molecules with a huge impact. J. Clin. Oncol. 27, 5848-5856. doi: 10.1200/JCO.2009.24.0317

Jaffray, C., Mendez, C., Denham, W., Carter, G., and Norman, J. (2000). Specific pancreatic enzymes activate macrophages to produce tumor necrosis factor-alpha: role of nuclear factor kappa B and inhibitory kappa B proteins. J. Gastrointest. Surg. 4, 370-377; discussion: 377-378. doi: 10.1016/S1091-255X(00)80015-3

Jones, S. A., Mills, K. H., and Harris, J. (2013). Autophagy and inflammatory diseases. Immunol. Cell Biol. 91, 250-258. doi: 10.1038/icb.2012.82

Kaiser, W. J., Upton, J. W., Long, A. B., Livingston-Rosanoff, D., Daley-Bauer, L. P., Hakem, R., et al. (2011). RIP3 mediates the embryonic lethality of caspase-8-deficient mice. Nature 471, 368-372. doi: 10.1038/nature09857

Kang, R., Livesey, K. M., Zeh, H. J., Loze, M. T., and Tang, D. (2010). HMGB1: a novel Beclin 1-binding protein active in autophagy. Autophagy 6, 1209-1211. doi: 10.4161/auto.6.8.13651

Kim, J., Choi, N. E., Oh, S. J., Park, S. J., and Kim, H. K. (2011). Combined expression of miR-122a, miR-1, and miR-200b can differentiate degraded RNA samples from liver, pancreas, and stomach. Pathol. Int. 61, 67-72. doi: 10.1111/j.1440-1827.2010.02615.x

Kong, X. Y., Du, Y. Q., Li, L., Liu, J. Q., Wang, G. K., Zhu, J. Q., et al. (2010). Plasma miR-216a as a potential marker of pancreatic injury in a rat model of acute pancreatitis. World J. Gastroenterol. 16, 4599-4604. doi: 10.3748/wjg.v16.i36.4599

Kusnierz-Cabala, B., Nowak, E., Sporek, M., Kowalik, A., Kuzniewski, M., Enguita, F. J., et al. (2015). Serum levels of unique miR-551-5p and endothelial-specific miR-126a-5p allow discrimination of patients in the early phase of acute pancreatitis. Pancreatology 15, 344-351. doi: 10.1016/j.pan.2015.05.475

Lankisch, P. G., Apte, M., and Banks, P. A. (2015). Acute pancreatitis. Lancet 386, 85-96. doi: 10.1016/S0140-6736(14)60649-8

Lawrie, C. H., Gal, S., Dunlop, H. M., Pushkaran, B., Liggins, A. P., Pulford, K., et al. (2008). Detection of elevated levels of tumour-associated microRNAs in serum of patients with diffuse large B-cell lymphoma. Br. J. Haematol. 141, 672-675. doi: 10.1111/j.1365-2141.2008.07077.x 
Lee, W. S., Huang, J. F., and Chuang, W. L. (2013). Outcome assessment in acute pancreatitis patients. Kaohsiung J. Med. Sci. 29, 469-477. doi: $10.1016 /$ j.kjms.2012.10.007

Lennox, K. A., and Behlke, M. A. (2011). Chemical modification and design of antimiRNA oligonucleotides. Gene Ther. 18, 1111-1120. doi: 10.1038/gt.2011.100

Liu, P., Xia, L., Zhang, W. L., Ke, H. J., Su, T., Deng, L. B., et al. (2014). Identification of serum microRNAs as diagnostic and prognostic biomarkers for acute pancreatitis. Pancreatology 14, 159-166. doi: 10.1016/j.pan.2014.03.019

Lundberg, A. H., Eubanks, J. W. III, Henry, J., Sabek, O., Kotb, M., Gaber, L., et al. (2000). Trypsin stimulates production of cytokines from peritoneal macrophages in vitro and in vivo. Pancreas 21, 41-51. doi: 10.1097/00006676-200007000-00050

Ma, X., Conklin, D. J., Li, F., Dai, Z., Hua, X., Li, Y., et al. (2015). The oncogenic microRNA miR-21 promotes regulated necrosis in mice. Nat. Commun. 6, 7151. doi: $10.1038 /$ ncomms 8151

Machado, M. T., Navega, S., Dias, F., de Sousa, M. J., Teixeira, A. L., and Medeiros, R. (2015). microRNAs for peripheral blood fraction identification: origin, pathways and forensic relevance. Life Sci. 143, 98-104. doi: 10.1016/j.lfs.2015.10.029

Maltby, S., Plank, M., Tay, H. L., Collison, A., and Foster, P. S. (2016). Targeting microRNA function in respiratory diseases: mini-review. Front. Physiol. 7:21. doi: 10.3389/fphys.2016.00021

Mareninova, O. A., Sung, K. F., Hong, P., Lugea, A., Pandol, S. J., Gukovsky, I., et al. (2006). Cell death in pancreatitis: caspases protect from necrotizing pancreatitis. J. Biol. Chem. 281, 3370-3381. doi: 10.1074/jbc.M511276200

Meher, S., Mishra, T. S., Sasmal, P. K., Rath, S., Sharma, R., Rout, B., et al. (2015). Role of biomarkers in diagnosis and prognostic evaluation of acute pancreatitis. J. Biomark. 2015:519534. doi: 10.1155/2015/519534

Mentula, P., and Leppaniemi, A. (2014). Position paper: timely interventions in severe acute pancreatitis are crucial for survival. World J. Emerg. Surg. 9:15. doi: 10.1186/1749-7922-9-15

Mikami, F., Lim, J. H., Ishinaga, H., Ha, U. H., Gu, H., Koga, T., et al. (2006). The transforming growth factor-beta-Smad3/4 signaling pathway acts as a positive regulator for TLR2 induction by bacteria via a dual mechanism involving functional cooperation with NF-kappaB and MAPK phosphatase 1-dependent negative cross-talk with p38 MAPK. J. Biol. Chem. 281, 22397-22408. doi: 10.1074/jbc.M602124200

Mitchell, P. S., Parkin, R. K., Kroh, E. M., Fritz, B. R., Wyman, S. K., PogosovaAgadjanyan, E. L., et al. (2008). Circulating microRNAs as stable blood-based markers for cancer detection. Proc. Natl. Acad. Sci. U.S.A. 105, 10513-10518. doi: 10.1073/pnas.0804549105

Ni, Q., Zhang, W., Sun, K., Yin, C., An, J., and Shang, D. (2014). In vitro effects of emodin on peritoneal macrophage intercellular adhesion molecule- 3 in a rat model of severe acute pancreatitis/systemic inflammatory response syndrome. Biomed. Rep. 2, 63-68. doi: 10.3892/br.2013.178

Prevot, P. P., Augereau, C., Simion, A., Van den Steen, G., Dauguet, N., Lemaigre, F. P., et al. (2013). Let-7b and miR-495 stimulate differentiation and prevent metaplasia of pancreatic acinar cells by repressing HNF6. Gastroenterology 145, 668-678.e663. doi: 10.1053/j.gastro.2013.05.016

Qian, D., Wei, G., Xu, C., He, Z., Hua, J., Li, J., et al. (2017). Bone marrowderived mesenchymal stem cells (BMSCs) repair acute necrotized pancreatitis by secreting microRNA- 9 to target the NF-kappaB1/p50 gene in rats. Sci. Rep. 7, 581. doi: 10.1038/s41598-017-00629-3

Qin, T., Fu, Q., Pan, Y. F., Liu, C. J., Wang, Y. Z., Hu, M. X., et al. (2014). Expressions of miR-22 and miR-135a in acute pancreatitis. J. Huazhong Univ. Sci. Technol. Med. Sci. 34, 225-233. doi: 10.1007/s11596-014-1263-7

Rivkin, M., Simerzin, A., Zorde-Khvalevsky, E., Chai, C., Yuval, J. B., Rosenberg, N., et al. (2016). Inflammation-induced expression and secretion of microRNA 122 leads to reduced blood levels of kidney-derived erythropoietin and anemia. Gastroenterology 151, 999-1010.e1013. doi: 10.1053/j.gastro.2016.07.031

Robb, T., Reid, G., and Blenkiron, C. (2017). Exploiting microRNAs as cancer therapeutics. Target. Oncol. 12, 163-178. doi: 10.1007/s11523-017-0476-7

Rouse, R., Rosenzweig, B., Shea, K., Knapton, A., Stewart, S., Xu, L., et al. (2017). MicroRNA biomarkers of pancreatic injury in a canine model. Exp. Toxicol. Pathol. 69, 33-43. doi: 10.1016/j.etp.2016.11.001

Roy, S. K., Srivastava, R. K., and Shankar, S. (2010). Inhibition of PI3K/AKT and MAPK/ERK pathways causes activation of FOXO transcription factor, leading to cell cycle arrest and apoptosis in pancreatic cancer. J. Mol. Signal. 5:10. doi: 10.1186/1750-2187-5-10

Shi, H., Liu, H., and Zhao, G. (2012). Effect of small interfering RNA transfection on FAK and DLC1 mRNA expression in OVCAR-3. Mol. Biol. Rep. 39, 9299-9306. doi: 10.1007/s11033-012-1724-7

Si, Y. L., Zhao, Y. L., Hao, H. J., Fu, X. B., and Han, W. D. (2011). MSCs: biological characteristics, clinical applications and their outstanding concerns. Ageing Res. Rev. 10, 93-103. doi: 10.1016/j.arr.2010.08.005

Smith, A., Calley, J., Mathur, S., Qian, H. R., Wu, H., Farmen, M., et al. (2016). The Rat microRNA body atlas; Evaluation of the microRNA content of rat organs through deep sequencing and characterization of pancreas enriched miRNAs as biomarkers of pancreatic toxicity in the rat and dog. BMC Genomics 17:694. doi: 10.1186/s12864-016-2956-Z

Soltoff, S. P., Carraway, K. L. III, Prigent, S. A., Gullick, W. G., and Cantley, L. C. (1994). ErbB3 is involved in activation of phosphatidylinositol 3-kinase by epidermal growth factor. Mol. Cell. Biol. 14, 3550-3558. doi: 10.1128/MCB.14.6.3550

Sood, P., Krek, A., Zavolan, M., Macino, G., and Rajewsky, N. (2006). Cell-typespecific signatures of microRNAs on target mRNA expression. Proc. Natl. Acad. Sci. U.S.A. 103, 2746-2751. doi: 10.1073/pnas.0511045103

Szafranska, A. E., Davison, T. S., John, J., Cannon, T., Sipos, B., Maghnouj, A., et al. (2007). MicroRNA expression alterations are linked to tumorigenesis and non-neoplastic processes in pancreatic ductal adenocarcinoma. Oncogene 26, 4442-4452. doi: 10.1038/sj.onc.1210228

Tang, D., Kang, R., Coyne, C. B., Zeh, H. J., and Lotze, M. T. (2012). PAMPs and DAMPs: signal 0s that spur autophagy and immunity. Immunol. Rev. 249, 158-175. doi: 10.1111/j.1600-065X.2012.01146.x

Tang, D., Kang, R., Livesey, K. M., Cheh, C. W., Farkas, A., Loughran, P., et al. (2010). Endogenous HMGB1 regulates autophagy. J. Cell Biol. 190, 881-892. doi: $10.1083 /$ jcb.200911078

Tenner, S., Baillie, J., DeWitt, J., and Vege, S. S. (2013). American College of Gastroenterology guideline: management of acute pancreatitis. Am. J. Gastroenterol. 108, 1400-1415; 1416. doi: 10.1038/ajg.2013.218

Tombol, Z., Szabo, P. M., Molnar, V., Wiener, Z., Tolgyesi, G., Horanyi, J., et al. (2009). Integrative molecular bioinformatics study of human adrenocortical tumors: microRNA, tissue-specific target prediction, and pathway analysis. Endocr. Relat. Cancer 16, 895-906. doi: 10.1677/ERC-09-0096

Treacy, J., Williams, A., Bais, R., Willson, K., Worthley, C., Reece, J., et al. (2001). Evaluation of amylase and lipase in the diagnosis of acute pancreatitis. ANZ J. Surg. 71, 577-582. doi: 10.1046/j.1445-2197.2001.02220.x

Usborne, A. L., Smith, A. T., Engle, S. K., Watson, D. E., Sullivan, J. M., and Walgren, J. L. (2014). Biomarkers of exocrine pancreatic injury in 2 rat acute pancreatitis models. Toxicol. Pathol. 42, 195-203. doi: $10.1177 / 0192623313512030$

Vernon, P. J., and Tang, D. (2013). Eat-me: autophagy, phagocytosis, and reactive oxygen species signaling. Antioxid. Redox Signal. 18, 677-691. doi: 10.1089 /ars.2012.4810

Wajant, H., Pfizenmaier, K., and Scheurich, P. (2003). Tumor necrosis factor signaling. Cell Death Differ. 10, 45-65. doi: 10.1038/sj.cdd. 4401189

Wang, J., Huang, W., Thibault, S., Brown, T. P., Bobrowski, W., Gukasyan, H. J., et al. (2017). Evaluation of miR-216a and miR-217 as Potential Biomarkers of Acute Exocrine Pancreatic Toxicity in Rats. Toxicol. Pathol. 45, 321-334. doi: $10.1177 / 0192623316678090$

Wildi, S., Kleeff, J., Mayerle, J., Zimmermann, A., Bottinger, E. P., Wakefield, L., et al. (2007). Suppression of transforming growth factor beta signalling aborts caerulein induced pancreatitis and eliminates restricted stimulation at high caerulein concentrations. Gut 56, 685-692. doi: 10.1136/gut.2006. 105833

Xie, P., Kondeti, V. K., Lin, S., Haruna, Y., Raparia, K., and Kanwar, Y. S. (2011). Role of extracellular matrix renal tubulo-interstitial nephritis antigen (TINag) in cell survival utilizing integrin (alpha)vbeta3/focal adhesion kinase (FAK)/ phosphatidylinositol 3-kinase (PI3K)/protein kinase B-serine/threonine kinase (AKT) signaling pathway. J. Biol. Chem. 286, 34131-34146. doi: 10.1074/jbc.M111.241778

Xu, M., Wang, K. N., Wu, K., and Wang, X. P. (2015). Pyrrolidine dithiocarbamate inhibits nuclear factor kappaB and toll-like receptor 4 expression in rats with acute necrotizing pancreatitis. Gut Liver 9, 411-416. doi: 10.5009/gnl14050 
Yan, X., and Chen, Y. G. (2011). Smad7: not only a regulator, but also a cross-talk mediator of TGF-beta signalling. Biochem. J. 434, 1-10. doi: 10.1042/BJ20101827

Yokoe, M., Takada, T., Mayumi, T., Yoshida, M., Isaji, S., Wada, K., et al. (2015). Japanese guidelines for the management of acute pancreatitis: Japanese guidelines 2015. J. Hepatobiliary Pancreat. Sci. 22, 405-432. doi: 10.1002/jhbp.259

Yu, C., Yu, X., Zhu, H. W., Li, X., Huang, L. H., Li, Z. Q., et al. (2016). Expression pattern of HMGB1 and its association with autophagy in acute necrotizing pancreatitis. Mol. Med. Rep. 14, 5507-5513. doi: 10.3892/mmr.20 16.5945

Yuan, Z., Zheng, Q., Fan, J., Ai, K. X., Chen, J., and Huang, X. Y. (2010). Expression and prognostic significance of focal adhesion kinase in hepatocellular carcinoma. J. Cancer Res. Clin. Oncol. 136, 1489-1496. doi: 10.1007/s00432-010-0806-y

Zhang, J., Ning, X., Cui, W., Bi, M., Zhang, D., and Zhang, J. (2015). Transforming growth factor (TGF)-beta-induced microRNA-216a promotes acute pancreatitis via Akt and TGF-beta pathway in mice. Dig. Dis. Sci. 60, 127-135. doi: 10.1007/s10620-014-3261-9

Zhang, X. X., Deng, L. H., Chen, W. W., Shi, N., Jin, T., Lin, Z. Q., et al. (2017). Circulating microRNA 216 as a marker for the early identification of severe acute pancreatitis. Am. J. Med. Sci. 353, 178-186. doi: 10.1016/j.amjms.2016.12.007

Zhao, Y., Wang, H., and Lu, M. (2016). Pancreatic acinar cells employ miRNAs as mediators of intercellular communication to participate in the regulation of pancreatitis-associated macrophage activation. Mediators Inflamm. 2016:6340457. doi: 10.1155/2016/6340457

Zhu, H., Huang, L., Zhu, S., Li, X., Li, Z., Yu, C., et al. (2016). Regulation of autophagy by systemic admission of microRNA-141 to target HMGB1 in 1-arginine-induced acute pancreatitis in vivo. Pancreatology 16, 337-346. doi: 10.1016/j.pan.2016.03.004

Conflict of Interest Statement: The authors declare that the research was conducted in the absence of any commercial or financial relationships that could be construed as a potential conflict of interest.

Copyright (c) 2017 Xiang, Tao, Xia, Qu, Song, Liu and Shang. This is an open-access article distributed under the terms of the Creative Commons Attribution License (CC $B Y)$. The use, distribution or reproduction in other forums is permitted, provided the original author(s) or licensor are credited and that the original publication in this journal is cited, in accordance with accepted academic practice. No use, distribution or reproduction is permitted which does not comply with these terms. 